Cite this: J. Mater. Chem. C, 2013, 1 5200

Received 29th April 2013

Accepted 1st July 2013

DOI: $10.1039 / \mathrm{c} 3 \mathrm{tc} 30805 \mathrm{~g}$

www.rsc.org/MaterialsC

\title{
The synthesis of rhodium substituted $\varepsilon$-iron oxide exhibiting super high frequency natural resonance $\uparrow$
}

\author{
Asuka Namai, ${ }^{a}$ Marie Yoshikiyo, ${ }^{a}$ Sayaka Umeda, ${ }^{a}$ Takayuki Yoshida, ${ }^{b}$ \\ Tatsuro Miyazaki, ${ }^{\mathrm{b}}$ Makoto Nakajima, ${ }^{\mathrm{c}}$ Keita Yamaguchi, ${ }^{\mathrm{d}}$ Tohru Suemoto ${ }^{\mathrm{d}}$ \\ and Shin-ichi Ohkoshi ${ }^{* a e}$
}

\begin{abstract}
In this study, we demonstrate a synthesis of rhodium substituted $\varepsilon$-iron oxide, $\varepsilon$ - $\mathrm{Rh}_{x} \mathrm{Fe}_{2-x} \mathrm{O}_{3}(0 \leq x \leq 0.19)$, nanoparticles in silica. The synthesis features a sol-gel method to coat the metal hydroxide sol containing $\mathrm{Fe}^{3+}$ and $\mathrm{Rh}^{3+}$ ions with a silica sol via hydrolysis of alkoxysilane to form a composite gel. The obtained samples are barrel-shaped nanoparticles with average long- and short-axial lengths of approximately $30 \mathrm{~nm}$ and $20 \mathrm{~nm}$, respectively. The crystallographic structure study using X-ray diffraction shows that $\varepsilon-\mathrm{Rh}_{x} \mathrm{Fe}_{2-x} \mathrm{O}_{3}$ has an orthorhombic crystal structure in the $P n a 2_{1}$ space group. Among the four nonequivalent substitution sites ( $A-D$ sites), $\mathrm{Rh}^{3+}$ ions mainly substitute into the $\mathrm{C}$ sites. The formation mechanism of $\varepsilon-\mathrm{Rh}_{x} \mathrm{Fe}_{2-x} \mathrm{O}_{3}$ nanoparticles is considered to be that the large surface area of the nanoparticles increases the contribution from the surface energy to Gibbs free energy, resulting in a different phase, $\varepsilon$-phase, becoming the most stable phase compared to that of bulk or single crystal. The measured electromagnetic wave absorption characteristics due to natural resonance (zero-field ferromagnetic resonance) using terahertz time domain spectroscopy reveal that the natural resonance frequency shifts from $182 \mathrm{GHz}\left(\varepsilon-\mathrm{Fe}_{2} \mathrm{O}_{3}\right)$ to $222 \mathrm{GHz}\left(\varepsilon-\mathrm{Rh}_{0.19} \mathrm{Fe}_{1.81} \mathrm{O}_{3}\right)$ upon rhodium substitution. This is the highest natural resonance frequency of a magnetic material, and is attributed to the large magnetic anisotropy due to rhodium substitution. The estimated coercive field for $\varepsilon-\mathrm{Rh}_{0.19} \mathrm{Fe}_{1.81} \mathrm{O}_{3}$ is as large as $28 \mathrm{kOe}$.
\end{abstract}

\section{Introduction}

As electronic devices and telecommunication technologies advance, the demand for electromagnetic wave absorbing materials to prevent electromagnetic interference is on the rise. Hence, the search for appropriate materials is an important materials science issue. ${ }^{1-3}$ Electromagnetic wave absorbing materials include magnetic materials and composite materials composed of electrically conductive and dielectric materials. Magnetic materials absorb electromagnetic waves by magnetic loss, and include spinel ferrite such as $\mathrm{Ni}_{x} \mathrm{Zn}_{1-x} \mathrm{Fe}_{2} \mathrm{O}_{4}(1 \mathrm{kHz}$ to $10 \mathrm{GHz}),{ }^{4-6}$ soft magnetic metal such as Fe powder $(1 \mathrm{kHz}$ to

${ }^{a}$ Department of Chemistry, School of Science, The University of Tokyo, 7-3-1 Hongo, Bunkyo-ku, Tokyo 113-0033, Japan.E-mail: ohkoshi@chem.s.u-tokyo.ac.jp

${ }^{b}$ Dowa Electronics Materials Co., Ltd., 1-3-1 Kaigandori, Minami-ku, Okayama 7028506, Japan

${ }^{c}$ Department of Physics, Chiba University, 1-33, Yayoicho, Inage Ward, Chiba-shi, Chiba 263-8522, Japan

${ }^{d}$ Institute for Solid State Physics, The University of Tokyo, 5-1-5 Kashiwanoha, Kashiwa, Chiba 277-8581, Japan

${ }^{e}$ CREST, JST, K's Gobancho, 7 Gobancho, Chiyoda-ku, Tokyo 102-0076, Japan

$\dagger$ Electronic supplementary information (ESI) available: The detailed information of synthesis, investigation of the sintering temperature, TEM study, crystal structure analysis, and magnetic properties. See DOI: 10.1039/c3tc30805g
$10 \mathrm{GHz}){ }^{7,8}$ and hexagonal ferrite such as $\mathrm{BaFe}_{12} \mathrm{O}_{19}(1 \mathrm{GHz}$ to $80 \mathrm{GHz}){ }^{9-11}$ Composite materials between electrically conductive and dielectric materials absorb electromagnetic waves through dielectric loss, and include composite materials between carbon materials and urethane foam $(1 \mathrm{MHz}$ to 10 $\mathrm{GHz})^{12,13}$ However, the prevalent use of wireless communications and radar systems in recent years, which use high frequency electromagnetic waves called millimeter waves (30$300 \mathrm{GHz}){ }^{14-17}$ requires the development of materials that absorb millimeter waves exceeding $100 \mathrm{GHz}$.

Our research group has recently demonstrated electromagnetic wave absorption of $\varepsilon$-iron oxide $\left(\varepsilon-\mathrm{Fe}_{2} \mathrm{O}_{3}\right)$, which exhibits a large coercive field $\left(H_{\mathrm{c}}\right)$ of $20 \mathrm{kOe},{ }^{18-28}$ due to magnetic loss at $182 \mathrm{GHz} .{ }^{29}$ Furthermore, we found that substituting $\varepsilon$-iron oxide with non-magnetic ions, such as $\mathrm{Al}^{3+}$ and $\mathrm{Ga}^{3+}$, can control the absorption frequency from $182 \mathrm{GHz}$ to $35 \mathrm{GHz},{ }^{29-31}$ and in 2012 , we achieved absorption frequencies above $182 \mathrm{GHz}$ up to 209 $\mathrm{GHz}$ with rhodium-substituted $\varepsilon$-iron oxide $\left(\varepsilon-\mathrm{Rh}_{x} \mathrm{Fe}_{2-x} \mathrm{O}_{3}\right){ }^{32}$

Herein we successfully develop a synthesis method of $\varepsilon-\mathrm{Rh}_{x} \mathrm{Fe}_{2-x} \mathrm{O}_{3}$ suitable for large-scale synthesis, and achieve an electromagnetic wave absorption frequency of $222 \mathrm{GHz}$, which exceeds the previously reported frequency and corresponds to the highest frequency for windows of air in millimeter waves $(220 \mathrm{GHz})$. 


\section{Results and discussion}

Previously, we synthesized $\varepsilon-\mathrm{Rh}_{x} \mathrm{Fe}_{2-x} \mathrm{O}_{3}$ nanoparticles in a $\mathrm{SiO}_{2}$ matrix using mesoporous silica as a template. ${ }^{32}$ In addition to being labor intensive, this method produces small quantities of $\varepsilon-\mathrm{Rh}_{x} \mathrm{Fe}_{2-x} \mathrm{O}_{3}$. In contrast, the present method employs a solgel method ${ }^{33,34}$ to synthesize $\varepsilon-\mathrm{Rh}_{x} \mathrm{Fe}_{2-x} \mathrm{O}_{3}$ by coating a metal hydroxide sol with a silica sol via hydrolysis of alkoxysilane to form a composite gel (Fig. 1a). This sol-gel synthesis has four steps: (i) generation of the metal hydroxide, (ii) formation of the silica matrix, (iii) sintering, and (iv) removal of the silica matrix (see the Experimental section). Nine samples (samples 1 to 9) with varying concentrations of $\mathrm{Fe}$ and $\mathrm{Rh}$ were synthesized.

Fig. 1b shows the transmission electron microscope (TEM) images of the obtained samples. The TEM images indicate that the samples are composed of barrel-shaped nanoparticles. The average long- and short-axial lengths of each sample are: (33 \pm 15) $\times(24 \pm 11) \mathrm{nm}(1),(35 \pm 16) \times(25 \pm 11) \mathrm{nm}(2),(36 \pm 17) \times$ $(26 \pm 12) \mathrm{nm}(3),(35 \pm 16) \times(27 \pm 12) \mathrm{nm}(4),(36 \pm 18) \times(27 \pm$ 14) $\mathrm{nm}(5),(29 \pm 17) \times(21 \pm 13) \mathrm{nm}(6),(27 \pm 18) \times(19 \pm 12)$ $\mathrm{nm}(7),(23 \pm 14) \times(16 \pm 9) \mathrm{nm}(8)$, and $(22 \pm 13) \times(16 \pm 9) \mathrm{nm}$ (9), respectively. The average aspect ratio (i.e., [long axis length]/ [short axis length]) of each sample is approximately 1.4 (Fig. S2 and Table $\mathrm{S} 2 \dagger)$.

The crystallographic structures of the obtained samples were studied using powder X-ray diffraction (XRD). As shown in Fig. 2a, the XRD patterns of the obtained samples indicated that the $\varepsilon$-phase was formed in all the samples. Besides the $\varepsilon$-phase, each sample contains the $\alpha$-phase or $\gamma$-phase. Fig. $2 b$ shows the phase ratios of the samples. The compositions for the $\varepsilon$-phase are $\quad \varepsilon-\mathrm{Fe}_{2} \mathrm{O}_{3} \quad(1), \quad \varepsilon-\mathrm{Rh}_{0.03} \mathrm{Fe}_{1.97} \mathrm{O}_{3} \quad(2), \quad \varepsilon-\mathrm{Rh}_{0.05} \mathrm{Fe}_{1.95} \mathrm{O}_{3} \quad$ (3), $\varepsilon-\mathrm{Rh}_{0.08} \mathrm{Fe}_{1.92} \mathrm{O}_{3}$ (4), $\varepsilon-\mathrm{Rh}_{0.10} \mathrm{Fe}_{1.90} \mathrm{O}_{3}$ (5), $\varepsilon-\mathrm{Rh}_{0.14} \mathrm{Fe}_{1.86} \mathrm{O}_{3}$ (6), $\varepsilon-\mathrm{Rh}_{0.15} \mathrm{Fe}_{1.85} \mathrm{O}_{3}(7), \varepsilon-\mathrm{Rh}_{0.18} \mathrm{Fe}_{1.82} \mathrm{O}_{3}(8)$, and $\varepsilon-\mathrm{Rh}_{0.19} \mathrm{Fe}_{1.81} \mathrm{O}_{3}(9)$ (Table 1). ${ }^{35}$ The lattice constants of the $\varepsilon$-phase are roughly the same regardless of the increases in the concentration of rhodium substitution, i.e., a-axis: $5.0917 \pm 0.0003 \AA$ (1) $\rightarrow$ $5.1110 \pm 0.0009 \AA$ (9), $b$-axis: $8.7857 \pm 0.0005 \AA$ (1) $\rightarrow 8.7980 \pm$ $0.0015 \AA$ (9), and $c$-axis: $9.4783 \pm 0.0008 \AA(1) \rightarrow 9.4722 \pm$ $0.0031 \AA(9)$ (Table 1), because the ionic radius of $\mathrm{Rh}^{3+}(0.67 \AA)$ is approximately the same as that of $\mathrm{Fe}^{3+}(0.65 \AA) .{ }^{36}$ Among the four non-equivalent substitution sites (A-D sites), $\mathrm{Rh}^{3+}$ ions mainly substitute into the $\mathrm{C}$ sites (Fig. 3). Additionally, as the amount of Rh substitution increases, the A- and B-sites also begin to be substituted. The details of the crystal structure analysis are described in the ESI. $\dagger$

Next we discuss the formation mechanism of $\varepsilon-\mathrm{Rh}_{x} \mathrm{Fe}_{2-x} \mathrm{O}_{3}$ nanoparticles in the present synthesis. In general, the bulk or single-crystal $\mathrm{Fe}_{2} \mathrm{O}_{3}$ transforms from $\gamma-\mathrm{Fe}_{2} \mathrm{O}_{3}$ to $\alpha-\mathrm{Fe}_{2} \mathrm{O}_{3}$ when the temperature is elevated. ${ }^{37}$ However, the large surface area of the nanoparticles increases the contribution from the surface energy to the Gibbs free energy $(G),{ }^{38}$ which is responsible for a different phase, $\varepsilon$-phase, becoming the most stable phase compared to that of bulk or single crystals. ${ }^{39-41}$ Fig. 4 depicts the particle size $(d)$ dependence of the free energy per molar volume $\left(G / V_{\mathrm{m}}\right)$ for the $\gamma$-phase, $\varepsilon$-phase, and $\alpha$-phase. ${ }^{42,43}$ The $G / V_{\mathrm{m}}$ versus $d$ curve of the $\varepsilon$-phase intercepts the $G / V_{\mathrm{m}}$ versus $d$ curves of the $\gamma$-phase and $\alpha$-phase, indicating that particle sizes in (a)

(i) Formation of metal hydroxide

(ii) Formation of silica matrix
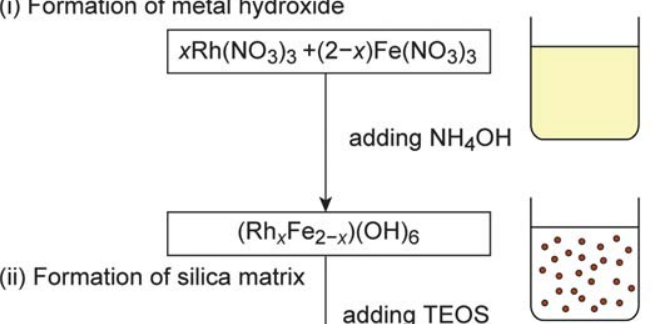

adding TEOS

centrifugation

$\left(\mathrm{Rh}_{x} \mathrm{Fe}_{2-\mathrm{x}}\right)(\mathrm{OH})_{6} / \mathrm{SiO}_{2}$

(iii) Sintering
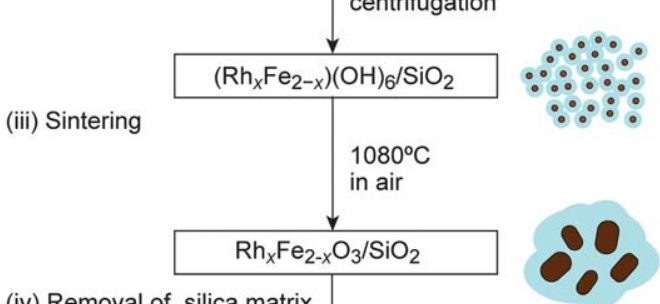

(iv) Removal of silica matrix

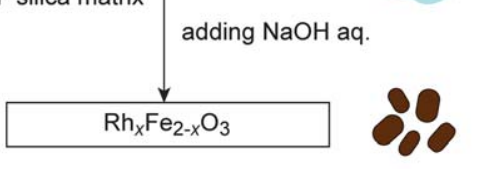

(b)
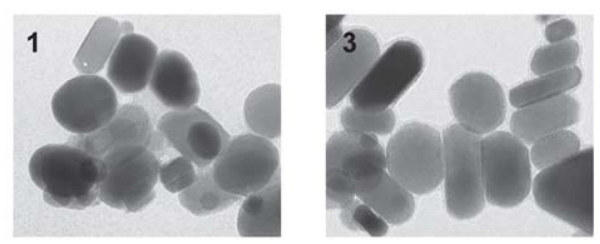

5
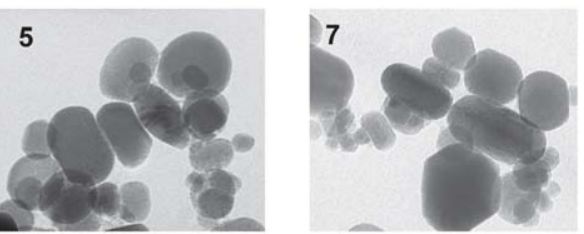

9

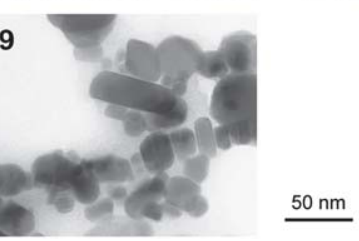

Fig. 1 (a) Schematic diagram of $\varepsilon-\mathrm{Rh}_{x} \mathrm{Fe}_{2-x} \mathrm{O}_{3}$ nanoparticle synthesis using the sol-gel method. (i) Aqueous ammonia is added to an aqueous solution containing both rhodium nitrate and ferric nitrate, yielding the sol of rhodium and iron hydroxide, $\left(\mathrm{Rh}_{x} \mathrm{Fe}_{2-x}\right)(\mathrm{OH})_{6}$ (shown in brown). (ii) TEOS $\left(\mathrm{Si}_{(}\left(\mathrm{OC}_{2} \mathrm{H}_{5}\right)_{4}\right)$ is added to the reaction solution to yield a complex gel, $\left(\mathrm{Rh}_{x} \mathrm{Fe}_{2-\chi}\right)(\mathrm{OH})_{6} / \mathrm{SiO}_{2}$, coated with a sol of silica (shown in light blue) via hydrolysis. (iii) Sintering the obtained gel in air yields $\mathrm{Rh}_{x} \mathrm{Fe}_{2-x} \mathrm{O}_{3}$ in silica. Sintering at $1080{ }^{\circ} \mathrm{C}$, which is higher than the glass transition temperature, causes nanoparticle aggregation and accelerates crystallization. (iv) $\mathrm{SiO}_{2}$ coated material is added to a $\mathrm{NaOH}$ solution to react and remove the $\mathrm{SiO}_{2}$ matrix as a $\mathrm{Na}_{2} \mathrm{SiO}_{3}$ solution. (b) TEM images of the final products after removing the silica matrix (samples $\mathbf{1}, \mathbf{3}, \mathbf{5}, \mathbf{7}$, and $\mathbf{9}$ ).

between these intercept points make the $\varepsilon$-phase as the most stable phase. In our method, synthesizing $\mathrm{Rh}_{x} \mathrm{Fe}_{2-x} \mathrm{O}_{3}$ as nanoparticles yields particle sizes that make the $\varepsilon$-phase most stable.

The reason for the difficulty to obtain a single $\varepsilon$-phase in the Rh-substituted system can be explained by the fact that the 
(a)

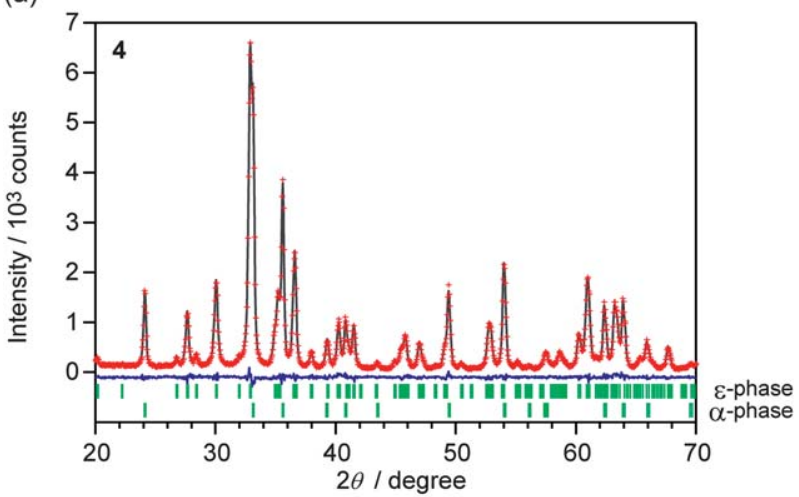

(b)

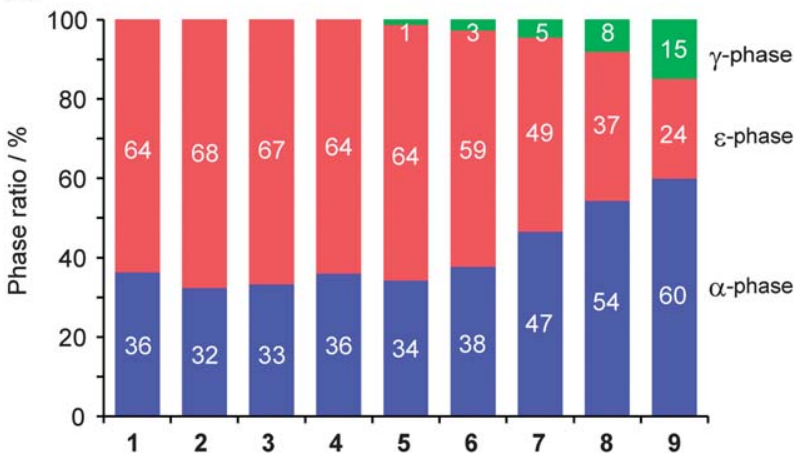

Fig. 2 (a) Powder X-ray diffraction pattern and Rietveld analysis result of sample 4. Red dots, black line, and blue line represent the observed values, calculated values, and the residual error, respectively. Bars denote Bragg peak positions of the $\varepsilon$ - and $\alpha$-phases. (b) Phase ratios of the samples obtained from the Rietveld analyses. Red, blue, and green represent $\varepsilon-, \alpha$-, and $\gamma$-phases, respectively.

chemical potential of $\mathrm{Rh}_{x} \mathrm{Fe}_{2-x} \mathrm{O}_{3}$ increases due to rhodium substitution. If the chemical potential of the $\varepsilon$-phase increases largely compared to the other two phases, the $G / V_{\mathrm{m}}$ versus $d$ curve of the $\varepsilon$-phase becomes relatively higher, narrowing the particle size range where the $\varepsilon$-phase is most stable. A narrower range explains the co-existence of the $\alpha$ - and $\gamma$-phases.

The following possibility can be cited as the reason that the particles have a barrel-shaped morphology. In $\left(\mathrm{Rh}_{x} \mathrm{Fe}_{2-x}\right)(\mathrm{OH})_{6} /$ $\mathrm{SiO}_{2}$, which is a precursor, a small amount of $\mathrm{Fe}^{3+}$ and $\mathrm{Rh}^{3+}$ ions is included in silica. Their presence reduces the glass transition (a)

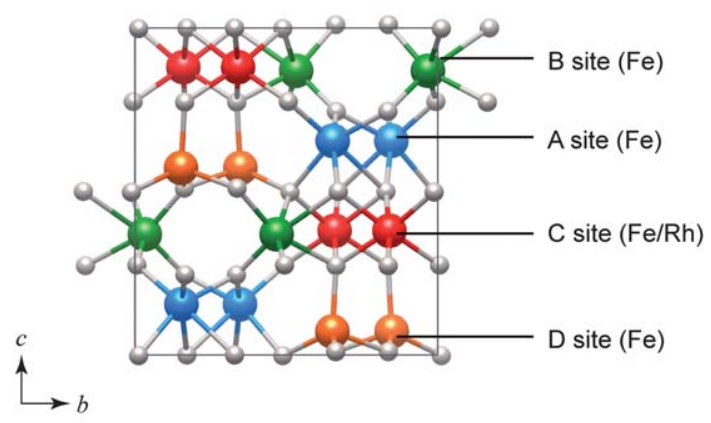

(b)

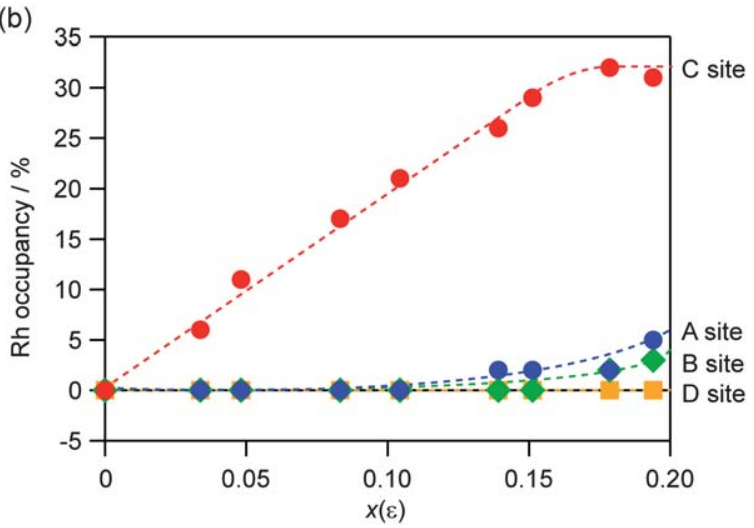

Fig. 3 (a) Crystallographic structure of $\varepsilon-\mathrm{Rh}_{x} \mathrm{Fe}_{2-x} \mathrm{O}_{3}$. (b) Rh occupancies versus substitution ratios of $x(\varepsilon)$ at the A-D sites. Dotted lines are a guide to the eye.

temperature compared to pure silica. ${ }^{44}$ Thus, aggregation of nanoparticles progresses in the silica matrix, which increases the crystallization degree and forms the barrel-shaped nanoparticles.

A terahertz time domain spectroscopy (THz-TDS) system was set up to measure electromagnetic wave absorption properties in the millimeter wave region (Fig. 5). Fig. 6 shows the measured millimeter wave absorption spectra of $\varepsilon-\mathrm{Rh}_{x} \mathrm{Fe}_{2-x} \mathrm{O}_{3}$. As we previously reported, ${ }^{29}$ sample 1 , which is $\varepsilon-\mathrm{Fe}_{2} \mathrm{O}_{3}$, shows an absorption peak centered at $182 \mathrm{GHz}$. Rhodium substitution increases the resonance absorption frequency: $187 \mathrm{GHz}(2)$, $192 \mathrm{GHz}(3), 197 \mathrm{GHz}(4), 202 \mathrm{GHz}$ (5), $207 \mathrm{GHz}$ (6), $213 \mathrm{GHz}$ (7), $217 \mathrm{GHz}(8)$, and $222 \mathrm{GHz}(9)$. Sample 9 breaks our previously

Table 1 Crystallographic parameters of $\varepsilon-\mathrm{Rh}_{x} \mathrm{Fe}_{2-x} \mathrm{O}_{3}$. Composition $x(\varepsilon)$, weight fraction $W(\varepsilon)$, lattice constant $(a, b, c)$, lattice volume $(V)$, and Rh occupancy at $\mathrm{A}-\mathrm{D}$ sites

\begin{tabular}{|c|c|c|c|c|c|c|c|c|c|c|}
\hline & & 1 & 2 & 3 & 4 & 5 & 6 & 7 & 8 & 9 \\
\hline$x(\varepsilon)$ & & 0 & 0.03 & 0.05 & 0.08 & 0.10 & 0.14 & 0.15 & 0.18 & 0.19 \\
\hline$W(\varepsilon) / \mathrm{wt} \%$ & & 64 & 68 & 67 & 64 & 64 & 59 & 49 & 37 & 24 \\
\hline$a / \AA$ & & $5.0917(3)$ & $5.0945(3)$ & $5.0966(3)$ & 5.0999 (3) & $5.1020(3)$ & $5.1055(3)$ & $5.1067(4)$ & $5.1095(5)$ & $5.1110(9)$ \\
\hline$b / \AA$ & & $8.7857(5)$ & $8.7867(5)$ & $8.7881(5)$ & $8.7900(5)$ & $8.7906(5)$ & $8.7941(6)$ & $8.7932(7)$ & $8.7951(9)$ & $8.798(2)$ \\
\hline$c / \AA$ & & $9.4783(8)$ & $9.4773(7)$ & $9.4761(8)$ & 9.4745 (7) & $9.4735(8)$ & $9.4734(9)$ & 9.4699 (11) & $9.471(2)$ & $9.472(3)$ \\
\hline$V / \AA^{3}$ & & $424.00(5)$ & $424.24(5)$ & $424.43(5)$ & $424.72(5)$ & $424.88(5)$ & $425.34(6)$ & $425.24(7)$ & $425.59(10)$ & $425.9(2)$ \\
\hline \multirow[t]{4}{*}{ Rh occupancy/\% } & A & 0 & 0 & 0 & 0 & 0 & $0(1)$ & $0(1)$ & $2(2)$ & $3(3)$ \\
\hline & B & 0 & $0(0)$ & $0(0)$ & $0(0)$ & $0(0)$ & $2(1)$ & $2(1)$ & $2(3)$ & $5(4)$ \\
\hline & $\mathrm{C}$ & 0 & $6(0)$ & $11(0)$ & $17(0)$ & $21(0)$ & $26(1)$ & $29(1)$ & $32(2)$ & $31(3)$ \\
\hline & D & 0 & 0 & 0 & 0 & 0 & 0 & 0 & 0 & 0 \\
\hline
\end{tabular}




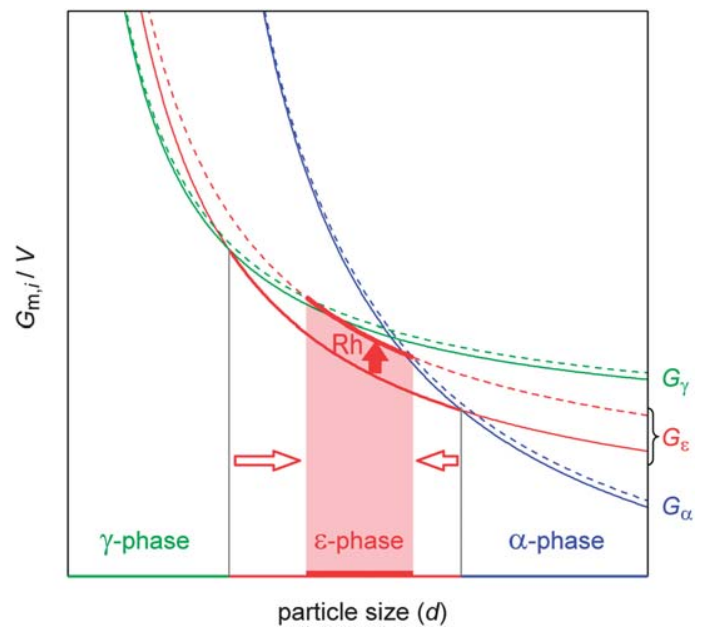

Fig. 4 Schematic curves of Gibbs free energy per unit volume for each phase of $\mathrm{Fe}_{2} \mathrm{O}_{3}$ (solid lines) and $\mathrm{Rh}_{x} \mathrm{Fe}_{2-x} \mathrm{O}_{3}$ (dotted lines), $\left(G_{\mathrm{i}} / V_{\mathrm{m}, \mathrm{i}}\right)$, versus particle size $(d)$ where $\mathrm{i}=\gamma, \varepsilon$, and $\alpha^{42,43} \mathrm{Green}$, red, and blue lines represent the $\gamma^{--}, \varepsilon^{-}$, and $\alpha$-phases, respectively. If rhodium substitution elevates the chemical potential of $\mathrm{Rh}_{x} \mathrm{Fe}_{2-x} \mathrm{O}_{3}$ and the increase of the chemical potential of the $\varepsilon$-phase is greater than those of the other two phases, the particle size range where the $\varepsilon$-phase is most stable becomes narrower. This explains why the $\alpha$-phase and $\gamma$-phase co-exist.

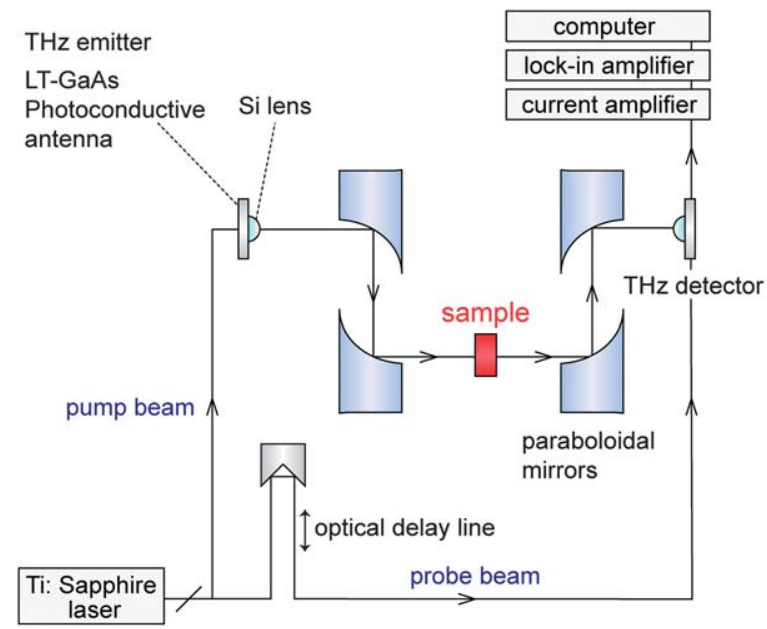

Fig. 5 Schematic diagram of the THz-TDS measurement system.

reported record of $209 \mathrm{GHz}$ for $\varepsilon-\mathrm{Rh}_{0.14} \mathrm{Fe}_{1.86} \mathrm{O}_{3},{ }^{32}$ and currently has the highest electromagnetic wave resonance frequency for a magnetic material.

The mechanism of electromagnetic wave absorption in magnetic materials is mainly caused by magnetic loss due to magnetic domain wall motion or natural resonance (zero-field ferromagnetic resonance). ${ }^{45}$ The observed high-frequency millimeter wave absorption in the present material is attributed to the natural resonance phenomenon. The mechanism is described below. When an electromagnetic wave is irradiated into a magnetic material, the magnetic component of the electromagnetic wave tilts the magnetization from the anisotropy field $\left(H_{\mathrm{a}}\right)$. Once the magnetization is tilted, it precesses around $H_{\mathrm{a}}$ due to the gyromagnetic effect. A resonance occurs at

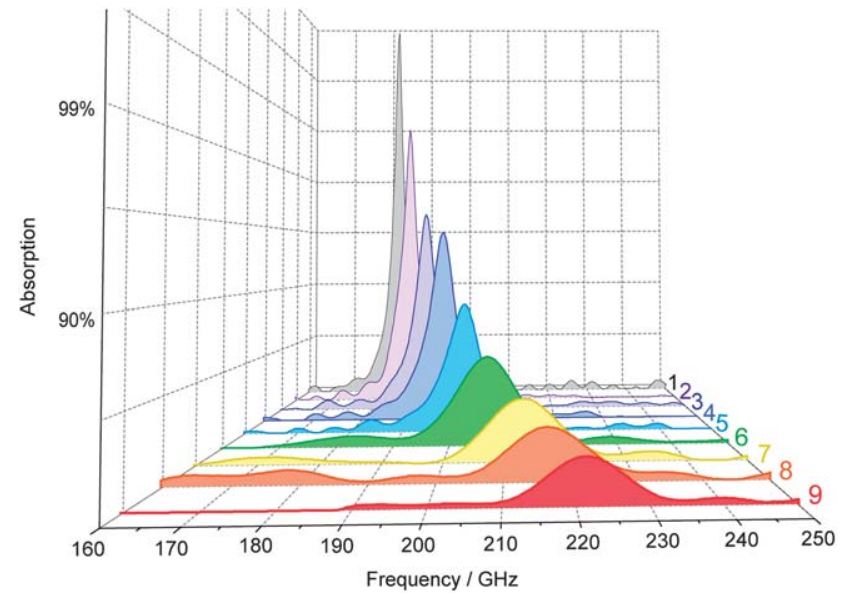

Fig. 6 Millimeter wave absorption spectra measured at room temperature.

the frequency matching this precession and causes electromagnetic wave absorption. The resonance frequency $f_{\mathrm{r}}$ can be expressed as: $f_{\mathrm{r}}=\nu H_{\mathrm{a}} / 2 \pi$, where $\nu$ is the gyromagnetic constant. Because a uniaxial magnetic anisotropic sample exhibits a proportional relationship between $H_{\mathrm{a}}$ and the coercive field $\left(H_{\mathrm{c}}\right)$, we investigated the $H_{\mathrm{c}}$ values of the samples.

Fig. 7 shows the magnetization versus external magnetic field curve at room temperature $(300 \mathrm{~K})$. Although samples 1 to 4 show an increase in $H_{\mathrm{c}}$ as the amount of rhodium substitution increases, i.e., $21.7 \mathrm{kOe}$ (1), $22.5 \mathrm{kOe}$ (2), $22.9 \mathrm{kOe}$ (3), and $23.9 \mathrm{kOe}$ (4), samples 5 to 9 exhibit a distortion in the hysteresis loop with a negative effect on $H_{\mathrm{c}}$, i.e., $23.9 \mathrm{kOe}(5), 22.6 \mathrm{kOe}(6), 15.5 \mathrm{kOe}(7)$, 4.2 kOe (8), and 0.9 kOe (9) (Fig. 8a, black open squares). To estimate the true $H_{\mathrm{c}}$ value of the $\varepsilon$-phase, we applied a correction that considered the contributions of the $\alpha$-phase and the $\gamma$-phase. The estimated $H_{\mathrm{c}}$ values for $\varepsilon-\mathrm{Rh}_{x} \mathrm{Fe}_{2-x} \mathrm{O}_{3}$ were $21.9 \mathrm{kOe}\left(\varepsilon-\mathrm{Fe}_{2} \mathrm{O}_{3}\right)$, $22.5 \mathrm{kOe}\left(\varepsilon-\mathrm{Rh}_{0.03} \mathrm{Fe}_{1.97} \mathrm{O}_{3}\right), 22.9$ kOe $\left(\varepsilon-\mathrm{Rh}_{0.05} \mathrm{Fe}_{1.95} \mathrm{O}_{3}\right), 24.0$ kOe $\left(\varepsilon-\mathrm{Rh}_{0.08} \mathrm{Fe}_{1.92} \mathrm{O}_{3}\right), 25.2$ kOe $\left(\varepsilon-\mathrm{Rh}_{0.10} \mathrm{Fe}_{1.90} \mathrm{O}_{3}\right), 26.3$ kOe $\left(\varepsilon-\mathrm{Rh}_{0.14} \mathrm{Fe}_{1.86} \mathrm{O}_{3}\right), \quad 26.7 \quad$ kOe $\quad\left(\varepsilon-\mathrm{Rh}_{0.15} \mathrm{Fe}_{1.85} \mathrm{O}_{3}\right), \quad 27.7 \quad$ kOe $\left(\varepsilon-\mathrm{Rh}_{0.18} \mathrm{Fe}_{1.82} \mathrm{O}_{3}\right)$, and $28.1 \mathrm{kOe}\left(\varepsilon-\mathrm{Rh}_{0.19} \mathrm{Fe}_{1.81} \mathrm{O}_{3}\right)$ (Fig. 8a, red solid circles). The last two $H_{\mathrm{c}}$ values exceed our previously reported value, and are the highest values among metal oxides to date. ESI contains detailed magnetic characteristics with respect to their temperature dependences. $\dagger$

The correlation between $H_{\mathrm{c}}$ and $f_{\mathrm{r}}$ demonstrates a monotonic increase in $f_{\mathrm{r}}$ with $H_{\mathrm{c}}$ (Fig. 8b). This means that rhodium substitution increases $H_{\mathrm{c}}$, which indicates an increase in the magnetic anisotropy, $H_{\mathrm{a}}$, and achieves a high $f_{\mathrm{r}}$ of $222 \mathrm{GHz}$.

\section{Conclusions}

Herein the highest natural resonance frequency to date of $222 \mathrm{GHz}$ is reported for a high frequency electromagnetic wave absorption material, $\varepsilon-\mathrm{Rh}_{x} \mathrm{Fe}_{2-x} \mathrm{O}_{3}$. This material was synthesized via the sol-gel method, which uses a liquid-phase reaction where water is the only solvent. This method is simple and is possible for industrial scale synthesis. Additionally, the lack of organic solvents and surfactants makes this method economical and environmentally friendly. 

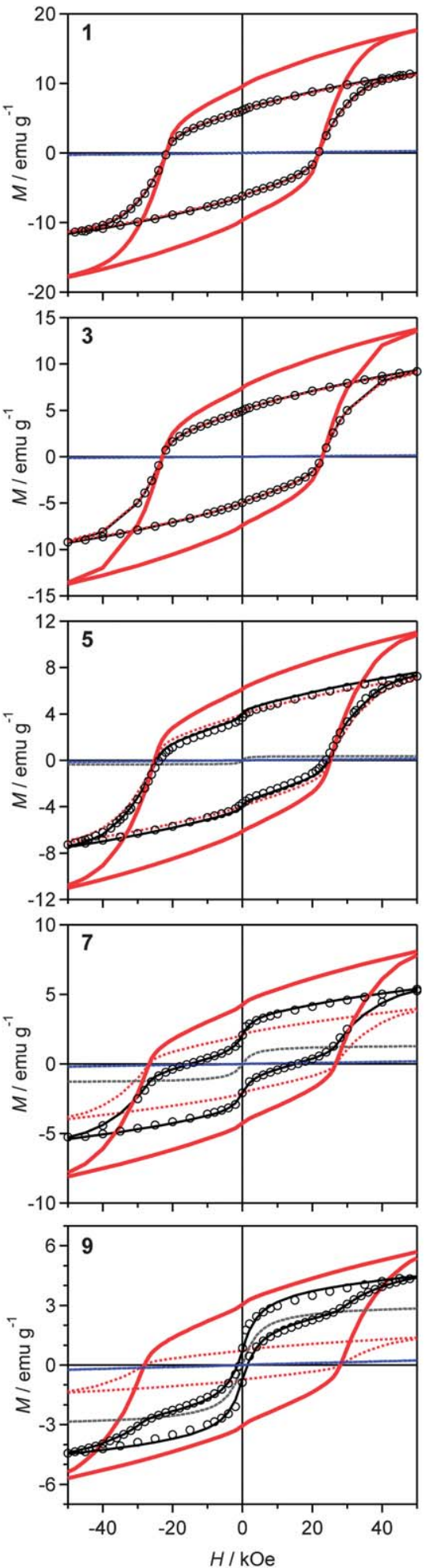

Fig. 7 Magnetization versus external magnetic field curves at $300 \mathrm{~K}$. Open circles are the observed values. Dotted lines represent contributions from each phase (red, blue, and gray dotted lines represent the $\varepsilon_{-}, \alpha-$, and $\gamma$-phases, respectively). Black solid lines are their sum. Red solid lines denote the estimated value for a single-phase $\varepsilon-\mathrm{Rh}_{x} \mathrm{Fe}_{2-x} \mathrm{O}_{3}$.

$220 \mathrm{GHz}$ is the highest-frequency window of air. Around this frequency, electromagnetic wave absorption by air is small. Consequently, this frequency band is expected as a carrier (a)

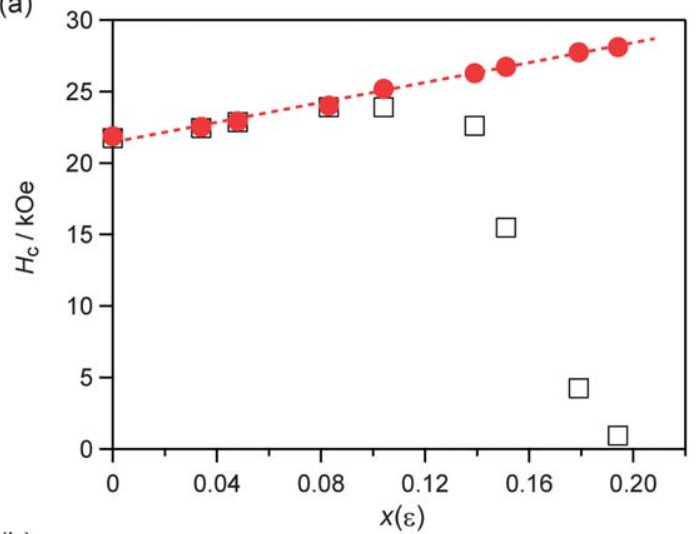

(b)

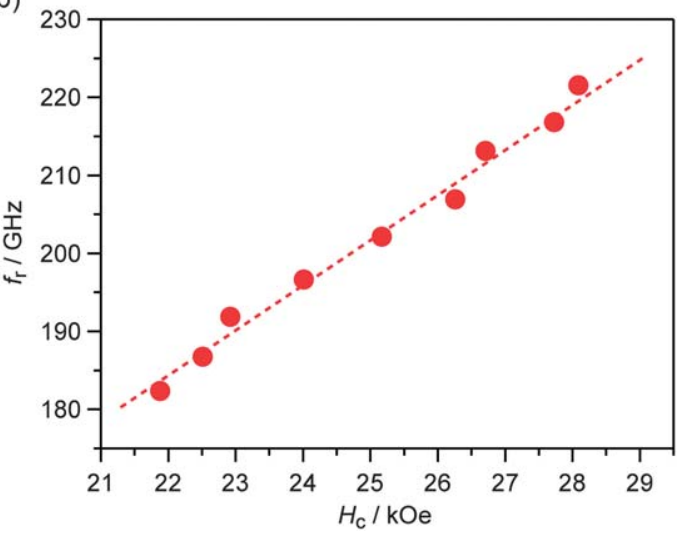

Fig. 8 (a) $H_{\mathrm{c}}$ versus $x(\varepsilon)$ plots. Solid red circles and black open squares represent the estimated $H_{\mathrm{c}}$ values and observed $H_{\mathrm{c}}$ values, respectively. Red dotted lines are a guide to the eye. (b) $f_{\mathrm{r}}$ versus $H_{\mathrm{c}}$ plots.

frequency for wireless communications. ${ }^{46-49}$ The materials developed herein should be useful as millimeter wave absorbing materials for unnecessary electromagnetic waves, which cause electromagnetic interference.

\section{Experimental section}

\section{Synthesis}

Samples 1-9 were prepared by the sol-gel method. First, $10.2 \mathrm{ml}$ of aqueous ammonia ( $13 \mathrm{~mol} \mathrm{dm}^{-3}$ ) was added while stirring $240 \mathrm{ml}$ of an aqueous solution with the following $\mathrm{Fe}\left(\mathrm{NO}_{3}\right)_{3}$ and $\mathrm{Rh}\left(\mathrm{NO}_{3}\right)_{3}$ concentrations: $\left(\mathrm{Fe}\left(\mathrm{NO}_{3}\right)_{3}, \mathrm{Rh}\left(\mathrm{NO}_{3}\right)_{3}\right)=\left(62.5 \times 10^{-3}\right.$, $\left.0 \mathrm{~mol} \mathrm{dm}^{-3}\right)(1),\left(61.3 \times 10^{-3}, 1.25 \times 10^{-3} \mathrm{~mol} \mathrm{dm}{ }^{-3}\right)(2)$, $\left(60.0 \times 10^{-3}, 2.50 \times 10^{-3} \mathrm{~mol} \mathrm{dm}^{-3}\right)(3),\left(58.8 \times 10^{-3}, 3.75 \times\right.$ $\left.10^{-3} \mathrm{~mol} \mathrm{dm}^{-3}\right)(4),\left(57.5 \times 10^{-3}, 5.00 \times 10^{-3} \mathrm{~mol} \mathrm{dm}^{-3}\right)(5)$, $\left(56.3 \times 10^{-3}, 6.25 \times 10^{-3} \mathrm{~mol} \mathrm{dm}{ }^{-3}\right)(6),\left(54.7 \times 10^{-3}, 7.81 \times\right.$ $\left.10^{-3} \mathrm{~mol} \mathrm{dm}^{-3}\right)(7),\left(53.1 \times 10^{-3}, 9.38 \times 10^{-3} \mathrm{~mol} \mathrm{dm}^{-3}\right)(8)$, and $\left(51.6 \times 10^{-3}, 10.9 \times 10^{-3} \mathrm{~mol} \mathrm{dm}^{-3}\right)(9)$. Successively, $22.6 \mathrm{ml}$ of tetraethoxysilane (TEOS) was added to this solution, and stirred for 20 hours. Then, the obtained gel was separated by centrifugation, washed with distilled water, and dried. The obtained dry powder was sintered in air for four hours at $1080{ }^{\circ} \mathrm{C}$. An aqueous solution of sodium hydroxide was added to the sintered powder, and stirred for one day at $60{ }^{\circ} \mathrm{C}$. The solution was centrifuged and washed to obtain the final 
products. We adopted the sintering temperature of $1080{ }^{\circ} \mathrm{C}$, since it had a high $\varepsilon$-phase ratio among the various sintering temperatures in the range of $1020-1300{ }^{\circ} \mathrm{C}$.

\section{Characterization}

Elemental analysis of the prepared samples was performed using an inductively coupled plasma mass spectroscopy (ICP-MS) system, Agilent Technologies 7700. The TEM images were collected with a JEOL JEM-2000EX transmission electron microscope, where the accelerating voltage was $200 \mathrm{kV}$. The XRD patterns were measured at $294 \mathrm{~K}$ using a Rigaku Ultima IV and a Rigaku RINT2100 with $\mathrm{Cu} \mathrm{K} \alpha$ radiation $(\lambda=1.5418 \AA)$, and Rietveld analyses were performed using the RIETAN-FP program. ${ }^{50}$

\section{Millimeter wave absorption measurement}

Electromagnetic wave absorption properties in the millimeter wave region were measured by a THz-TDS system, where a pump-probe measurement system was used. Ultra short pulse with a time duration of $20 \mathrm{fs}$ and a center photon energy of $1.55 \mathrm{eV}$ generated from a mode-locked Ti:sapphire femtosecond pulse laser at a repetition rate of $76 \mathrm{MHz}$ was divided into a pump and probe beam. The pump pulse was irradiated into a dipole type low-temperature-grown GaAs photoconductive antenna, which generated a $\mathrm{THz}$ pulse. The $\mathrm{THz}$ pulse was condensed with a Si lens and a set of paraboloidal mirrors and was irradiated into the sample. The electric field of the transmitted $\mathrm{THz}$ pulse wave formed in the time domain was obtained by changing the delay time between the pump and the probe pulses. Powder-form samples were filled in paper cells $(6.5 \mathrm{~mm} \times 6.5 \mathrm{~mm} \times 4.8 \mathrm{~mm}$ for samples $1-8$ and $6.5 \mathrm{~mm} \times$ $6.5 \mathrm{~mm} \times 8 \mathrm{~mm}$ for sample 9) with filling ratios of 29-31 vol\%. In the present millimeter wave absorption study, the sample thickness of at least $3 \mathrm{~mm}$ was necessary to avoid interference from the edges of the cell. The obtained spectra were calibrated as spectra of $30 \mathrm{vol} \%$ of the $\varepsilon$-phase, $4.8 \mathrm{~mm}$ thickness.

\section{Magnetic property measurement}

The magnetic properties were measured using a superconducting quantum interference device (SQUID) magnetometer, Quantum Design, MPMS 7. Field cooled magnetization (FCM) curves were measured in the temperature range of 4-550 K, where the cooling rate was $-1 \mathrm{~K} \mathrm{~min}^{-1}$. Magnetic hysteresis loops were measured at $300 \mathrm{~K}$.

\section{Acknowledgements}

The present research was supported partly by the Core Research for Evolutional Science and Technology (CREST) program of the Japan Science and Technology Agency (JST); a Grant-in-Aid for Young Scientists (S) from the Japan Society for the Promotion of Science (JSPS); DOWA Technofund; the Asahi Glass Foundation; a Grant for the Global COE Program "Chemistry Innovation through Cooperation of Science and Engineering"; Advanced Photon Science Alliance (APSA) from the Ministry of Education, Culture, Sports, Science and Technology of Japan (MEXT); JSPS
KAKENHI Grant Number 24850004; Office for Gender Equality, the University of Tokyo; the Cryogenic Research Center, the University of Tokyo; the Center for Nano Lithography \& Analysis, the University of Tokyo, supported by MEXT. M. Y. is grateful to Advanced Leading Graduate Course for Photon Science (ALPS) and JSPS Research Fellowships for Young Scientists. We are grateful to Ms Y. Kitano for her technical support and Mr Y. Kakegawa and Mr H. Tsunakawa for collecting the TEM images.

\section{References and notes}

1 K. J. Vinoy and R. M. Jha, in Radar Absorbing Materials, Kluwer, Boston, 1996.

2 S. Celozzi, R. Araneo and G. Lovat, in Electromagnetic Shielding, Wiley-Interscience: IEEE Press, New Jersey, 2008.

3 C. M. Watts, X. Liu and W. J. Padilla, Adv. Mater., 2012, 24, OP98.

4 Y. Naito and K. Suetake, IEEE Trans. Magn., 1971, 19, 65.

5 R. K. Selvan, V. Krishnan, C. O. Augustin, H. Bertagnolli, C. S. Kim and A. Gedanken, Chem. Mater., 2008, 20, 429.

6 F. Wang, J. Liu, J. Kong, Z. Zhang, X. Wang, M. Itoh and K. Machida, J. Mater. Chem., 2011, 21, 4314.

7 M. Matsumoto and Y. Miyata, IEEE Trans. Magn., 1997, 33, 4459.

8 Z. Yu, Z. Yao, N. Zhang, Z. Wang, C. Li, X. Han, X. Wub and Z. Jiang, J. Mater. Chem. A, 2013, 1, 4571.

9 S. Sugimoto, S. Kondo, K. Okayama, H. Nakamura, D. Book, T. Kagotani, M. Homma, H. Ota, M. Kimura and R. Sato, IEEE Trans. Magn., 1999, 35, 3154.

10 Y. Chen, T. Sakai, T. Chen, S. D. Yoon, A. L. Geiler, C. Vittoria and V. G. Harris, Appl. Phys. Lett., 2006, 88, 062516.

11 K. A. Korolev, J. S. McCloy and M. N. Afsar, J. Appl. Phys., 2012, 111, 07E113.

12 Y. Yang, M. C. Gupta, K. L. Dudley and R. W. Lawrence, Adv. Mater., 2005, 17, 1999.

13 Z. Liu, G. Bai, Y. Huang, Y. Ma, F. Du, F. Li, T. Guo and Y. Chen, Carbon, 2007, 45, 821.

14 M. J. W. Rodwell, in High Speed Integrated Circuit Technology, towards $100 \mathrm{GHz}$ Logic, World Scientific, Singapore, 2001.

15 K. C. Huang and Z. Wang, in Millimeter Wave Communication Systems, Wiley-IEEE Press, New Jersey, 2011.

16 J. Capmany and M. Novak, Nat. Photonics, 2007, 1, 319.

17 D. Dawson, L. Samoska, A. K. Fung, K. Lee, R. Lai, R. Grundbacher, P.-H. Liu and R. Raja, IEEE Microw. Wireless Compon. Lett., 2005, 15, 874.

18 J. Jin, S. Ohkoshi and K. Hashimoto, Adv. Mater., 2004, 16, 48.

19 E. Tronc, C. Chanéac and J. P. Jolivet, J. Solid State Chem., 1998, 139, 93.

20 M. Popovici, M. Gich, D. Niznansky, A. Roig, C. Savii, L. Casas, E. Molins, K. Zaveta, C. Enache and J. Sort, Chem. Mater., 2004, 16, 5542.

21 J. Jin, K. Hashimoto and S. Ohkoshi, J. Mater. Chem., 2005, 15, 1067.

22 K. Kelm and W. Mader, Z. Anorg. Allg. Chem., 2005, 631, 2383. 
23 E. Tronc, C. Chaneac, J. P. Jolivet and J. M. Greneche, J. Appl. Phys., 2005, 98, 053901.

24 M. Kumoo, J. Rehspringer, A. Hutlova, C. D'Orleans, S. Vilminot, C. Estoumes and D. Niznansky, Chem. Mater., 2005, 17, 1106.

25 T. Nakamura, Y. Yamada and K. Yano, J. Mater. Chem., 2006, 16, 2417.

26 M. Hermanek and R. Zboril, Chem. Mater., 2008, 20, 5284.

27 Y. Kusano, T. Fujii, J. Takada, M. Fukuhara, A. Doi, Y. Ikeda and M. Takano, Chem. Mater., 2008, 20, 151.

28 J. Tucek, R. Zboril, A. Namai and S. Ohkoshi, Chem. Mater., 2010, 22, 6483.

29 A. Namai, S. Sakurai, M. Nakajima, T. Suemoto, K. Matsumoto, M. Goto, S. Sasaki and S. Ohkoshi, J. Am. Chem. Soc., 2009, 131, 1170.

30 S. Ohkoshi, S. Kuroki, S. Sakurai, K. Matsumoto, K. Sato and S. Sasaki, Angew. Chem., Int. Ed., 2007, 46, 8392.

31 S. Sakurai, S. Kuroki, H. Tokoro, K. Hashimoto and S. Ohkoshi, Adv. Funct. Mater., 2007, 17, 2278.

32 A. Namai, M. Yoshikiyo, K. Yamada, S. Sakurai, T. Goto, T. Yoshida, T. Miyazaki, M. Nakajima, T. Suemoto, H. Tokoro and S. Ohkoshi, Nat. Commun., 2012, 3, 1035.

33 L. L. Hench and J. K. West, Chem. Rev., 1990, 90, 33.

34 B. L. Cushing, V. L. Kolesnichenko and C. J. O'Connor, Chem. Rev., 2004, 104, 3893.

35 The values of $x$ for each phase of $\mathrm{Rh}_{x} \mathrm{Fe}_{2-x} \mathrm{O}_{3}[x(\varepsilon), x(\alpha)$, and $x(\gamma)$ ] were obtained as follows. Sintering precursors at $1180{ }^{\circ} \mathrm{C}(x=0), 1160{ }^{\circ} \mathrm{C}(0.12), 1140{ }^{\circ} \mathrm{C}(0.30)$, and $1140{ }^{\circ} \mathrm{C}$ (0.36) gave single-phase nanoparticles of $\alpha-\mathrm{Rh}_{x} \mathrm{Fe}_{2-x} \mathrm{O}_{3}$. Rietveld analysis on the obtained $\alpha-\mathrm{Rh}_{x} \mathrm{Fe}_{2-x} \mathrm{O}_{3}$ nanoparticles revealed a linear increase in the lattice constants ( $a$ and $c$ ) and lattice volume $(V)$ as $x(\alpha)$ increased. This linear relationship was used to obtain $x(\alpha)$ in $\alpha-\mathrm{Rh}_{x} \mathrm{Fe}_{2-x} \mathrm{O}_{3}$ for samples 1-9. For samples 1-4, which were composed of the $\varepsilon$ - and $\alpha$-phases, the $x(\varepsilon)$ values in the $\varepsilon-\mathrm{Rh}_{x} \mathrm{Fe}_{2-x} \mathrm{O}_{3}$ phase were obtained by considering the compositions of the $\alpha$-phase, the weight ratio between the phases obtained from the Rietveld analysis, and the quantity of Rh in the entire sample obtained from the ICPMS measurement. This revealed a linear relationship between the lattice constants $(a, b$, and $c)$ and lattice volume $(V)$ and $x(\varepsilon)$ for the $\varepsilon-\mathrm{Rh}_{x} \mathrm{Fe}_{2-x} \mathrm{O}_{3}$ phase. This linear relationship was used to obtain $x(\varepsilon)$ in $\varepsilon-\mathrm{Rh}_{x} \mathrm{Fe}_{2-x} \mathrm{O}_{3}$ of samples 5-9. For samples 5-9, which were composed of the $\varepsilon, \alpha$, and $\gamma$-phases, the $x(\gamma)$ values in the $\gamma-\mathrm{Rh}_{x} \mathrm{Fe}_{2-x} \mathrm{O}_{3}$ phase were obtained by considering the compositions of the $\varepsilon$ - and $\alpha$-phases, the weight ratio between the phases obtained from the Rietveld analysis, and the quantity of $\mathrm{Rh}$ in the entire sample. The details are described in the ESI $\dagger$ 36 R. D. Shannon, Acta Crystallogr., Sect. A: Cryst. Phys., Diffr., Theor. Gen. Crystallogr., 1976, 32, 751.

37 K. J. Standley, in Oxide Magnetic Materials, Clarendon Press, Oxford, 1972.

38 H. Zhang and J. F. Banfield, J. Mater. Chem., 1998, 8, 2073.

39 J. M. McHale, A. Auroux, A. J. Perrotta and A. Navrotsky, Science, 1997, 277, 788.

40 H. L. Wen, Y. Y. Chen, F. S. Yen and C. H. Huang, Nanostruct. Mater., 1999, 11, 89.

41 S. Ohkoshi, Y. Tsunobuchi, T. Matsuda, K. Hashimoto, A. Namai, F. Hakoe and H. Tokoro, Nat. Chem., 2010, 2, 539. 42 S. Sakurai, A. Namai, K. Hashimoto and S. Ohkoshi, J. Am. Chem. Soc., 2009, 131, 18299.

43 S. Ohkoshi, S. Sakurai, J. Jin and K. Hashimoto, J. Appl. Phys., 2005, 97, 10K312.

44 S. N. Houde-Walter, J. M. Inman, A. J. Dent and G. N. Greaves, J. Phys. Chem., 1993, 97, 9330.

45 S. Chikazumi, in Physics of Ferromagnetism, Oxford University Press, New York, 1997.

46 J. W. Archer, R. Lai, R. Grundbacher, M. Barsky, R. Tsai and P. Reid, IEEE Microw. Wireless Compon. Lett., 2001, 11, 4.

47 M. Urteaga, D. Scott, S. Krishnan, Y. Wei, M. Dahlstrom, Z. Griffith, N. Parthasarathy and M. J. W. Rodwell, IEEE J. Solid-State Circuits, 2003, 38, 1451.

48 D. Dawson, L. Samoska, A. K. Fung, K. Lee, R. Lai, R. Grundbacher, P.-H. Liu and R. Raja, IEEE Microw. Wireless Compon. Lett., 2005, 15, 874.

49 I. Minin, in Microwave and Millimeter Wave Technologies: from Photonic Bandgap Devices to Antenna and Applications, Intech Press, New York, 2010.

50 F. Izumi and K. Momma, Solid State Phenom., 2007, 130, 15. 